\title{
Application of membrane processes in mining and mineral processing
}

\author{
Marinela Panayotova ${ }^{1, *}$ and Vladko Panayotov ${ }^{1,2}$ \\ ${ }^{1}$ University of Mining and Geology, 1700 Sofia, Bulgaria \\ ${ }^{2}$ BAS - Technical Sciences, 1000 Sofia, Bulgaria
}

\begin{abstract}
Sustainable mining and mineral processing is of paramount importance for producing metals needed for our society development. Membrane processes are able to contribute to the comprehensive extraction of metals from mined ores, while at the same time decrease the amounts of used water and reagents and ensure discharge to the environment of wastewater meeting the legislation requirements. Membranebased technologies are still underused in metals obtaining although their development and price have made their application affordable. The paper presents in brief membrane processes and displays examples of their application in various areas of mining and mineral processing, such as coping with acid mine drainage and mine influenced water, recovery of metals, reagents and water in hydrometallurgy, recovery of lithium from brines, and treatment of wastewater. Emphasis is placed on pressure driven membrane processes, as well as on the very recent studies in the area. Advantages of membrane processes application in mining and mineral processing are pointed out as well as constrains to be overcome.
\end{abstract}

\section{Introduction}

The sustainable development of our society and our normal life needs metals - ferrous, nonferrous and minor. For the present, all metals can be ensured in required amounts only by the "chain" mining - extractive metallurgy (mineral processing, hydrometallurgy, pyrometallurgy and electrometallurgy).

Ores extraction by mining and metals extraction by mineral processing and/or hydrometallurgy are related with generation and /or use of different aqueous streams. When sulphide minerals, such as pyrite are disturbed by mining activities and exposed to oxygen and water chemical reactions take place - finally leading to formation of acidic water containing sulphates and ions of various metals in elevated concentrations, i.e. the so called acid mine drainage (AMD) is formed. When it is not treated, the AMD can result in a considerable pollution to both soil and groundwater [1].

Membrane technologies have been and are being studied for removing and concentrating different metals from AMD [2-5].

Generally, flotation is most effectively carried out with clean water. Changes in water quality are unwanted because this could affect the reagent regimes, finally resulting in compromise of the flotation performance. It is known that water quality impacts the flotation results and the following negative effects can be observed: loss of separation efficiency, loss of recovery, loss of concentrate grade, contamination of products [6]. At the same time the minerals industry is being requested to save freshwater by using recycled water and to minimize the discharge of wastewater into the environment. Since the flotation efficiency can be affected by the water quality, different approached have been and are being developed to cope with the problem. Among them membrane technologies are being studied to remove metal ions and improve the quality of water used in flotation [7].

Nowadays the shortage of many metals necessary for the modern economies, in combination with the increasing demand and the need to use low-grade ores, requires more efficient technologies for metals extraction. Hydrometallurgy plays a key role in processing and recovery of metals from challenging raw materials. Traditionally hydrometallurgical flowsheet includes i) ores leaching, ii) purification of the pregnant leach solution (PLS) by solvent extraction followed by stripping or by ion exchange followed by elution, and iii) metal recovery - where in many cases electrowinning is applied. In the latter case use of membrane technologies to preconcentrate PLS is regarded recently as an way for lowering the energy consumption, enhancing the recovery of valuable metals and ensuring high recovery of reagents and fresh water [8].

Lithium ( $\mathrm{Li}$ ) is a very important metal in the production of rechargeable batteries, ceramics and glass, as well as lubricating greases. It is used in metallurgy (as casting additive, flux and alloying element) and in many other industries. Lithium can be extracted from either hard rock minerals and brines. Salt brines represent the most abundant lithium sources. They comprise approximately $60 \%$ of all known lithium deposits [9]. In the recent 10 15 years extensive work has been carried out to improve

\footnotetext{
$\overline{{ }^{*} \text { Corresponding author: marichim@mgu.bg }}$
} 
Li recovery from brines by applying membrane technologies.

Membrane technologies have been and are being widely studied and applied to recover valuable metals from wastewater from mineral processing and extractive metallurgy while at the same time ensuring high quality of treated water. Even more, they may be applied also to leachates from mining waste.

Figure 1 presents a summary of the possible applications of membrane technologies in metals extraction.

Membrane technologies have been existing for around 50 years, but they are still not widely used in the general mining industry. That is why this paper aims at shedding some light on the opportunities presented by the membrane processes for more profound use of resources and sustainable production of metals, with an emphasis on the recent (3-4) years.

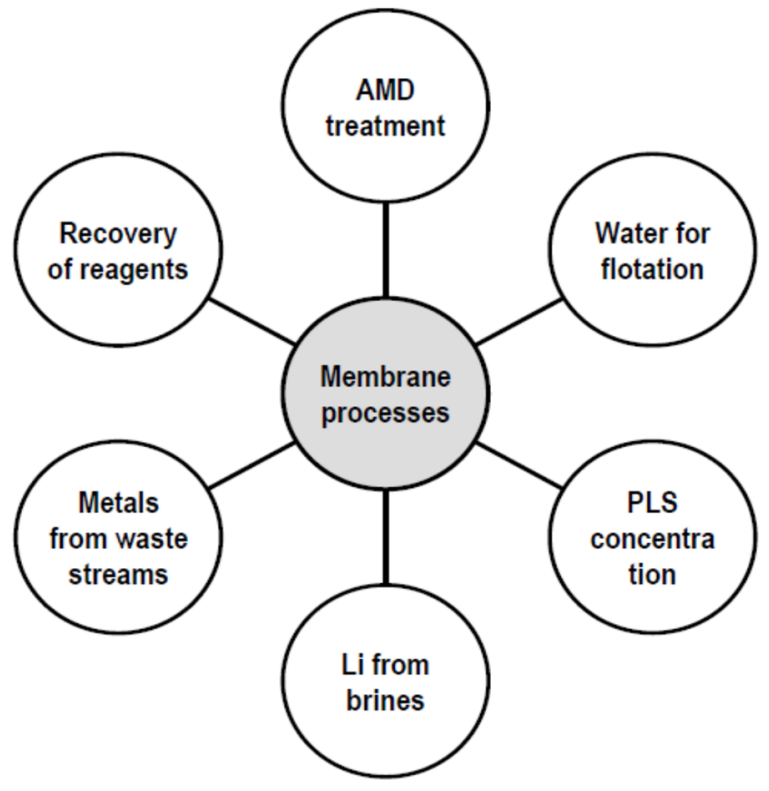

Fig. 1. Possible applications of membrane technologies in metals extraction

\section{Membrane technologies in brief}

Membranes are semi-permeable structures or films of materials that allow only certain species or substances to pass and prevent passage of others.

Different forces can drive substances to pass trough membrane - Table 1 [10].

Although there are some studies devoted to application of emulsion liquid membranes and supported liquid membranes techniques for extraction and recovery of metals from liquids (wastewater, waste liquids) the works on these applications are not so many and they are dealing with specific cases of extraction $[13,14]$.

Membrane distillation that can operate at low temperatures $\left(60-90^{\circ} \mathrm{C}\right)$ enables the use of waste heat and thus seems a promising technology [15].

Forward osmosis is considered also a promising technology since it does not require a pressure application.
Table 1. Membrane processes classification based to the driving force

\begin{tabular}{|c|c|}
\hline Driving force & Membrane process \\
\hline $\begin{array}{c}\text { Pressure } \\
\text { difference }\end{array}$ & $\begin{array}{c}\text { Microfiltration - MF, Ultrafiltration - } \\
\text { UF, Nanofiltration - NF, Reverse } \\
\text { osmosis - RO }\end{array}$ \\
\hline $\begin{array}{c}\text { Electric } \\
\text { potential } \\
\text { difference }\end{array}$ & $\begin{array}{c}\text { Electrodialysis - ED, membrane } \\
\text { electrolysis - ME, (membrane) electro- } \\
\text { deionization -EDI, membrane } \\
\text { electrophoresis }\end{array}$ \\
\hline $\begin{array}{c}\text { Chemical } \\
\text { potential } \\
\text { difference }\end{array}$ & $\begin{array}{c}\text { Pervaporation, Per-traction, Dialysis } \\
\text { Vapour permeation, Liquid } \\
\text { membranes - LM, Forward osmosis - } \\
\text { FO }\end{array}$ \\
\hline $\begin{array}{c}\text { Temperature } \\
\text { difference }\end{array}$ & Membrane distillation - MD \\
\hline
\end{tabular}

However, both MD and FO are evaluated as emerging membrane-based technologies and still enough studies and data are absent on their application [16].

Electrodialysis has been studied as a method for recovering the reagents and metals from stripping solutions [17], separating and recovering lithium from brines [18-20] and even in the mineral extraction from deep see water [21]. However these applications are still in the study stage.

The most studied and used membrane techniques, including in mining, mineral processing and extractive metallurgy, are based on a pressure difference between membrane feed and permeate sides - Table 2.

PDMPs performance generally is evaluated according to the following characteristics:

- Trans-membrane flux $\left(\mathrm{J}_{\mathrm{v}}\right)[\mathrm{m} / \mathrm{s}]$ :

$$
\left.\mathrm{J}_{\mathrm{v}}=\mathrm{V}_{\mathrm{p}} / \mathrm{S}_{\mathrm{m}} \times \mathrm{t}_{\mathrm{p}}\right)
$$

where: $V_{p}$ - the volume of permeate $\left[\mathrm{m}^{3}\right], \mathrm{S}_{\mathrm{m}}$ - the surface of the membrane in contact with the flux $\left[\mathrm{m}^{2}\right], \mathrm{t}_{\mathrm{p}}$ - the time [s]

- Solute passage $\mathrm{P}$

$$
\mathrm{P}=\mathrm{C}_{\mathrm{p}} / \mathrm{C}_{\mathrm{f}}
$$

where $\mathrm{C}_{\mathrm{f}}$ is the solute concentration in the feed and $\mathrm{C}_{\mathrm{p}}$ its concentration in the permeate

- Solute rejection (retention), in \%

$$
\mathrm{R}=(1-\mathrm{P}) \times 100=\left(1-\mathrm{C}_{\mathrm{p}} / \mathrm{C}_{\mathrm{f}}\right) \times 100
$$

- Selectivity coefficient

$$
\left(\alpha_{1 / 2}\right)=\mathrm{P}_{1} / \mathrm{P}_{2}=\left[\mathrm{C}_{\mathrm{p}} / \mathrm{C}_{\mathrm{f}}\right]_{1} /\left[\mathrm{C}_{\mathrm{p}} / \mathrm{C}_{\mathrm{f}}\right]_{2}
$$

When retentate is concentrated to a small volume, the volume concentration factor (VCF) is determined

$$
\mathrm{VCF}=\mathrm{V}_{\mathrm{f}} / \mathrm{Vr}
$$

where $V_{f}$ is the volume of the feed at the start of filtration and $\mathrm{V}_{\mathrm{r}}$ is the retentate (concentrate) volume.

- Recovery 
Table 2. Pressure driven membrane processes (PDMPs) [1, 10-12]

\begin{tabular}{|c|c|c|c|c|}
\hline Process & Microfiltration & Ultrafiltration & Nanofiltration & Reverse osmosis \\
\hline Membrane material ${ }^{1}$ & $\begin{array}{c}\text { CC, PP, PS, PVDF, } \\
\text { CA }\end{array}$ & $\begin{array}{c}\text { CC, PS, PVDF, CA, } \\
\text { TFC }\end{array}$ & CA, PVDF, TFC & CA, TFC \\
\hline Membrane structure & $\begin{array}{c}\text { porous, symmetric } \\
\text { or asymmetric }\end{array}$ & $\begin{array}{c}\text { microporous, } \\
\text { asymmetric }\end{array}$ & $\begin{array}{c}\text { tight porous asymmetric, } \\
\text { thing film composite }\end{array}$ & $\begin{array}{c}\text { dense, semi- porous, } \\
\text { asymmetric }\end{array}$ \\
\hline Retained diameter, $\mu \mathrm{m}$ & $0,1-10$ & $0,01-0,1$ & $0,001-0,01$ & $<0,001$ \\
\hline MWCO $^{3}$, kilo Dalton & $100-500$ & $20-150$ & $2-20$ & $0,2-2$ \\
\hline Operating pressure, bar & $<2$ & $<10$ & $<35$ & $<75$ \\
\hline Separation mechanism & size exclusion & size exclusion & $\begin{array}{c}\text { combination of size } \\
\text { exclusion and solution } \\
\text { diffusion }\end{array}$ & solution diffusion \\
\hline Permeate flux & high & medium & low \\
\hline $\begin{array}{c}\text { Usual module } \\
\text { configuration }\end{array}$ & $\begin{array}{c}\text { tubular, hollow } \\
\text { fiber }\end{array}$ & $\begin{array}{c}\text { tubular, hollow fiber, } \\
\text { spiral wound, plate-and- } \\
\text { frame }\end{array}$ & $\begin{array}{c}\text { tubular, spiral wound, } \\
\text { hollow fiber }\end{array}$ & $\begin{array}{c}\text { tubular, spiral wound, } \\
\text { plate-and-frame }\end{array}$ \\
\hline Examples of rejection & $\begin{array}{c}\text { bacteria, micro- } \\
\text { particles, fat, oil, } \\
\text { grease, colloids }\end{array}$ & $\begin{array}{c}\text { macromolecules - } \\
\text { proteins, pigments, } \\
\text { polysaccharides, } \\
\text { detergents, viruses }\end{array}$ & $\begin{array}{c}\text { high molecular weight } \\
\text { compounds, polyvalent } \\
\text { ions }\end{array}$ & $\begin{array}{c}\text { high and low } \\
\text { molecular weight } \\
\text { compounds, poly- and } \\
\text { monovalent ions }\end{array}$ \\
\hline
\end{tabular}

${ }^{1}$ CC - ceramic, PP - polypropylene, PS - polysulfonic, PVDF - polyvinilidene fluoride, CA - cellulose acetate, TFC - thin film composite membrane 2 The RO and NF membrane presently of choice worldwide is the polyamide TFC. TFC membranes, composed of a strong asymmetric support membrane and a thin dense polyamide toplayer, have a higher permeability and can be used at higher temperatures at a broader $\mathrm{pH}$ range, compared to the others. Cellulose acetate membranes are chlorine resistant while TFC membranes have low resistance to chlorine.

${ }^{3}$ Molecular weight cut off range

${ }^{4}$ Solutes dissolve in the membrane material, then diffuse through it due to the concentration gradient. The separation is based on the differences in the solubilities of the solutes in the membrane and the different diffusion rates.

${ }^{5}$ There are four membrane configuration types for treatment systems: plate-and-frame (flat membranes sandwiched between membrane support plates which are arranged in stacks), spiral wound (flat sheet membranes separated by spacer screens and wrapped around a central core of a perforated collecting tube), hollow fiber, and tubular.

$$
\text { Recovery, } \%=m_{P, \text { end }} / m_{F, \text { ini }}
$$

where - $m_{P, \text { end }}$ - permeate mass at the end of the experiment, $\mathrm{m}_{\mathrm{F}}$, ini - feed mass at the beginning of the experiment.

The permeate flux in membrane separation process, which determines its productivity, depends on the properties of the membrane, properties of the feed solution, trans-membrane-pressure, solute mass transfer coefficient (which influences the concentration polarization), membrane fouling.

The main factors influencing the selectivity and permeability of PDMPs are the pressure applied over the treated water (working pressure), the temperature and acidity of the treated water, the concentration and nature of the salts dissolved in the treated water.

The concentration polarisation and the fouling are the main factors affecting membrane performance. Concentration polarisation is the observed differential solute concentration between membrane surface and bulk stream. It is reversibly influenced by operation parameters. The fouling is formation of deposits on the membrane surface. It is irreversibly influenced by operation parameters.

\section{Membrane technologies for treating AMD and mine influenced water}

The high concentrations of sulfate ions and metals in AMD pose a severe risk to the environment.
Most often lime is added to AMD to raise its $\mathrm{pH}$ and precipitate the dissolved toxic harmful metals. However, the sludge produced by this process has no economic value and has to be disposed of, covering large areas of land. Acid mine drainage can be effectively processed and made satisfactory for discharge using membrane technology.

Studies on membrane processes application for treating AMD commenced at the 90-ties of the previous century with an emphasis mainly on RO.

Probably one of the earliest applications of membrane technologies was at Cananea de Mexicana where a fullscale RO - based plant was installed in 1997 to treat AMD - with copper recovery directly from concentrate - thus the process was paid back within 6 months [22].

$\mathrm{NF}$ and RO (single pass units) were applied successfully at the Kennecott Utah Copper's Bingham Canyon Mine Water Treatment Plant, now property of Rio Tinto Group, to treat AMD ( $\mathrm{pH} 2,9$ - 3,4, $\mathrm{SO}_{4}{ }^{2-}-73,8$ $\mathrm{g} / \mathrm{L}, \mathrm{Mg}-9,9 \mathrm{~g} / \mathrm{L}, \mathrm{Al}-5,96 \mathrm{~g} / \mathrm{L}$, and $\mathrm{Ca}, \mathrm{Cu}, \mathrm{Fe}, \mathrm{Mn}, \mathrm{Zn}$ - in the range of $0,150-0,599 \mathrm{~g} / \mathrm{L}$, TDS - $92 \mathrm{~g} / \mathrm{L}$ ) and contaminated groundwater. The solute retention for all pollutants was higher than $97 \%$. The main encountered problem was gypsum scaling [23].

Zhong and co-authors tested commercial polyamide ultra-low pressure reverse osmosis (ULPRO) and nanofiltration (NF) membranes for their ability to remove heavy metal ions from AMD. Rejections achieved were $97 \%$ and $95 \%$ respectively pointing at the possibility to recover metals from the concentrate obtained. In addition ULPRO removed also a major part of the dissolved 
monovalent ions thus decreasing the total water conductivity by $96 \%$ and rendering the treated water suitable for irrigation purposes [24].

Results from studies and applications of RO, ED, NF and UF for the treatment of AMD and mine influenced water (MIW), carried out till 2008, are comprehensively presented and discussed by Mortazavi [25].

A group of scientists at Freiberg University of Mining and Technology studied (2008 - 2010) the applicability of different RO and NF membranes for treating AMD. Experiments were carried out at two different pressures of 20 and 30 bar and at two different concentration levels in order to resemble the concentration range of actual AMD found in the mining industry. The results showed that NF membranes (NF99, DK, GE) successfully treated AMD, the heavy metals rejection was $>98 \%$ at higher fluxes and at lower pressure (consequently energy consumption) compared to RO. The DK membrane performed in the best way since it showed the highest rejection even at low studied pressure (20 bar) and high AMD concentration. The treatment has also been successfully conducted on a large scale in order to check its applicability at a commercial scale [3, 26, 27].

In 2010 the Interstate Technology and Regulatory Council (ITRC) at the Environmental Research Institute of the States announced that any one of the pressure driven membrane processes can be implemented to treat MIW, including surface and ground water [12]. According to ITRC the treatment goal(s) determine the process selection. The application of a given PDMPs generally depends on the: a) water quality requirements for the permeate (i.e., product water), b) location and source of water needing treatment, c) availability of utilities, d) options to dispose concentrates (retentate), e) quality of the water to be treated. Actually RO was successfully used to treat MIW rich in sulfates and TDS to achieve drinking water standards [28].

The EMalahleni water treatment plant (South Africa) was a solution for treating the coal mining industry influenced water in a reclamation project. AMD was collected from 3 mining sites, neutralized by lime addition which removed iron, magnesium and aluminium. After the clarification water was treated with UF and RO to produce potable quality water. The membrane separation step was repeated 3 times to maximize water recovery and minimize the concentrate volume. The feed water contained mainly calcium, magnesium and sulphate, with a small concentration of monovalent ions (sodium, chloride and potassium), and iron, manganese and aluminium [2, 29].

Dow NF 270 polyamide thin film and a TriSep TS 80 polyamide thin film nanofiltration membranes were studied for their ability to remove and concentrate ionic species from MIW in wide range of $\mathrm{pH}$ values of the polluted water [30]. The study proved that NF can be successfully used to achieve metal recovery objectives and meet discharge standards.

A study was carried out with the aim to assess the applicability of RO and NF to treat AMD from gold mines, as well as the main operational conditions. The results pointed that the NF had a higher potential to treat the AMD than the RO, since NF ensures higher permeate flux and satisfactory solutes retention efficiency. The best results were obtained with NF270 membrane at feed $\mathrm{pH}$ of 5,5 where the maximum water recovery rate was $60 \%$. The estimated capital cost of the UF-NF unit at an effluent volumetric flow rate of $15 \mathrm{~m}^{3} / \mathrm{h}$ was US\$ 131250,00 , and the operational cost was $0,263 \mathrm{US} \$ / \mathrm{m}^{3}$ of effluent [31].

A very recent study has been carried out at a pilotscale level with real AMD in order to determine and estimate the operating conditions for using a commercial NF membrane (NF270) to recover water and concentrate copper, as well as to find how NF can be coupled with SX for the selective copper recovery [32]. The water was acidic $(\mathrm{pH} 3,5)$ with high conductivity $(5510 \mu \mathrm{S} / \mathrm{cm})$ and high concentrations of some pollutants, in $\mathrm{g} / \mathrm{L}: 4,67 \mathrm{SO}_{4}{ }^{2-}$ , 0,53 Cu, 0,38 Al, 44,70 Zn, 72,0 Mn. The study has proved that the combined NF-SX technology achieved a high recovery of water and copper from AMD. Thus, freshwater consumption can be reduced and wastewater treatment costs can be decreased.

Since UF works on low operating pressure (consequently energy consumption) and at high water recovery, studies have been carried out to use this membrane process to treat AMD and MIW. However, a means had to be found to modify the pollutants so that they could be retained by the larger pores of UF membranes. Here came to aid application of surfactants and polymers and micellar enhanced ultrafiltration (MEUF) and polymer enhanced ultrafiltration (PEUF) were proposed. PEUF is based on use of water-soluble polymer to complex metallic ions. The formed complexes possess a higher molecular weight than the MWCO of the membrane. The complex is retained by the UF membrane. Further, the retentate can be treated to recover metallic ions and polymeric agent for reuse. The polymers used (polyacrylic acid, polyethyleneimine, diethylaminoethyl cellulose and humic acid) achieved selective separation and high recovery of heavy metals with low energy requirements [33].

The MEUF is based on the use of a surfactant in the feed stream of the UF process. Dissolved ions which are intended to be separated are attracted by oppositely charged surfactant molecules. They attach to the surface of a micelle formed when the concentration of the surfactant exceeds the critical micelle concentration. Thus formed large ion-micelle complexes can be retained by the ultrafiltration membrane. Ions that are not attached to the surface of a micelle can penetrate through the membrane pores because of their small size. A drawback of MEUF is that it can cause secondary pollution to the environment if the used surfactants are leaked to the permeate. That is why, biosurfactants have been developed [15]. MEUF was successfully applied at pilot level to remove $\mathrm{Cd}$ and $\mathrm{Cu}$ from phosphorous rich real wastewaters [34].

Very recently a combination of FO and RO processes was proposed for treatment of mining wastewater [5]. Results from a pilot scale FO-RO (with a capacity of 1 $\mathrm{m}^{3} /$ day) pointed that this process could offer reduction in use of energy, chemicals, and piping infrastructure. 


\section{Membrane technologies for PLS concentration}

Mainly gold and copper mines have invested in membrane systems to concentrate their PLS [4].

In the early 90-ties of the previous century HW Process Technologies, Inc. installed at Freeport McMoran Phelps-Dodge Rod Mill El Paso one NF and two RO systems to treat $\mathrm{H}_{2} \mathrm{SO}_{4}$-based $\mathrm{Cu}$-bearing PLS from heap leaching in order to increase the feed copper concentration to the SX/EW plant, reuse the permeate from the second $\mathrm{RO}$ system as rinse water, while the concentrate from the 1 st RO system is passed also through a NF system. The $\mathrm{NF}$ concentrate was directed to copper refinery, while NF permeate was sent to $\mathrm{Cu}$ dissolving. In this way a ZeroLiquid (waste)-Discharge was achieved [22].

In 1999 the same company obtained an US patent for method for separating gold and/or silver from copper or other contaminant metals in which a NF membrane is used to form a retentate containing most of the multivalent metal cyanide complexes and a permeate, containing most of the precious metal cyanide complexes [35]. In next stages the precious metal(s) can be recovered from the permeate and the other valuable but non-precious metals - from the retentate where they present as multivalent metal cyanide complexes.

Minera Yanacocha is the largest gold producer in South America. Its mining and processing operations are in the Andes Mountains at height in the range 3500 - 4100 meters. The gold is extracted by heap leaching with diluted cyanide solution $(30-50 \mathrm{mg} / \mathrm{L}$ free cyanide). Seven RO modules are installed (initial installation in 2003) at Yanacocha complex $\left(250 \mathrm{~m}^{3} / \mathrm{h}\right.$ each one $)$ and five excess water treatment plants, two carbon plants for recovering precious metals, and two Merrill Crowe processing plants [4]. During the rainy season, the PLS is being diluted and RO plants are used to dewater the PLS making the Merrill-Crowe gold extraction process more effective. Additional RO plants are installed to remove the cyanide and metals left and to allow the permeate water to be discharged and the concentrate to be returned to the extraction process. At the same time chlorine consumption (for cyanide destruction) is reduced by $75 \%$ and overall operating cost is $70 \%$ less than that of a conventional precipitation plant [22].

Because of the harmful impact of copper-cyanide complexes on the gold extraction process, the use of NF for separating $\mathrm{Au}(\mathrm{CN})_{2}{ }^{-}$from $\mathrm{Cu}(\mathrm{CN})_{3}{ }^{2-}$ has been studied. Soldenhoff and co-authors reviewed some patented NF processes for gold processing designed to ensure separation of $\mathrm{Au}(\mathrm{CN})_{2}{ }^{-}$from $\mathrm{Cu}(\mathrm{CN})_{3}{ }^{2-}$ in copper-rich cyanide solutions [36]. This separation can be realized by treating either the PLS from cyanide leaching operations or the loaded eluate from activated carbon extraction.

Treatment of copper-gold cyanide PLS from heap leaching where it is fractionated into a small, $1 / 10^{\text {th }}$, volume copper concentrated stream and a large, $9 / 10^{\text {th }}$, volume gold-bearing stream has been proposed [37]. The copper stream is processed further by sulfide-acid-reneutralization-treatment to recover copper and return cyanide back to the process. The gold-(or gold-silver) permeate stream is processed to recover gold and the cyanide (concentrated by a membrane process from the barren solution) can be returned to the leaching. Thus both permeates and concentrates from the applied membrane processes provide added value.

Studies have been conducted also on membrane processes application to PLS from a pressure-oxidation (POX) of refractory gold ores [38, 39]. POX represents a hydrometallurgical oxidation of concentrated ore pulp under high pressure (20 bar) and temperature (135-200 ${ }^{\circ} \mathrm{C}$ ). During the pressure oxidation process, the sulfide in the host mineral matrix is oxidized by oxygen, thus producing soluble metal sulfates and sulfuric acid. In this way, the gold originally occluded in the sulfide minerals is completely released, allowing further high gold recovery by cyanide leaching. POX is efficient process for refractory gold ores but it generates a large volume of liquid effluents, characterized by high acidity and substantial metal content, and some of metals $\mathrm{Cu}, \mathrm{Co}$ and $\mathrm{Ni}$ ) are of great economic value. The aim was to concentrate metals, and recover acid and water by applying combination of UF, NF and RO. The UF process is used as a pretreatment to avoid presence of suspended solids in the feed to NF system. NF membrane concentrates $\mathrm{Cu}, \mathrm{Co}$ and $\mathrm{Ni}$. An average concentration factor of 2 was observed for metals in the NF retentate. This concentration was favorable to subsequent recovery processes of metals $(\mathrm{Co}, \mathrm{Ni}$ and $\mathrm{Cu}$ ). The NF permeate (a metals-free solution with a low concentration of acid) is passed to the RO stage. There the acid is concentrated in RO retentate (with 2,5 times higher concentration of the $\mathrm{H}_{2} \mathrm{SO}_{4}$ and low impurity content - totally $0,58 \mathrm{mg} / \mathrm{L}$ ) and could be recirculated to control acidity in the POX process. The RO permeate was water with quality for industrial reuse in the company. The best performance at a pilot-scale operation was while operating at recovery rate of $90 \%, 40-50 \%$, and $50 \%$ for UF, NF, and RO, correspondingly. The total estimated cost of the proposed treatment was US\$ $1,137 / \mathrm{m}^{3}$ of effluent, including the neutralisation of UF and NF concentrates. A long-term work in a mining company validated suitability of the proposed treatment scheme. The same working group conducted further studies to find the most chemically stable membranes in order to increase the process sustainability [40]. Commercially available NF membranes (NF90, NF270, MPF34, DK, Duracid) and RO membranes (BW30, LP, TFC-HR, XN45, and SG) were assessed in terms of key performance parameters. The DK (as NF) and SG (as RO) membrane showed the highest capability for application in POX effluent treatment.

Application of membrane process has been studied and proposed also for recovering nickel from spent nickel electrolyte after electrowinning of $\mathrm{Ni}$ from purified PLS of the base metal refinery in the PGM cycle (Bushveld Complex, South Africa) [41]. Energy costs limit the recovery of nickel in the electrowinning unit to $50 \%$ thus making the recycling of the spent nickel electrolyte significant for cost-effective nickel production. In the "classical scheme" four units are necessary for nickel concentration and sending back to the cycle. They are replaced by one NF unit. The retentate stream where 
nickel is concentrated is recycled back to the nickel electrowinning cells together with the sodium sulphate to ensure the needed conductivity while the permeate is recycled back to the leaching circuit in order to reduce the overall sulphuric acid consumption of the base metal refinery.

Very recently a study has presented a promising process chain for the separation of $\mathrm{Ge}$ and $\mathrm{Re}$ from an acidic multicomponent PLS obtained by bioleaching [42]. The proposed treatment chain includes consecutively MF, $\mathrm{NF}$, and RO. For the MF pretreatment rotating ceramic and polymeric (MV020) membrane filters are proposed. Over $99 \%$ of the leached sludge particles are retained and can be recycled for bioleaching as leaching bacteria are still present. In the further step the sterile solution is passed to NF system. With NF99HF it is possible to remove all cations $\left(\mathrm{Co}^{2+}, \mathrm{Cu}^{2+}, \mathrm{Fe}^{3+}, \mathrm{Zn}^{2+}\right)$ at retention $\geq$ $99 \%$ and Mo at retention $>97 \%$. Concentrate is sent to the refining stage while the permeate stream is transferred to the next RO step (with RO90 membrane). There the Ge is concentrated in the retentate while Re passes to permeate. Both high tech elements can be further extracted from the corresponding streams by solvent extraction or adsorption.

\section{Membrane technologies in obtaining lithium from brines}

According to some estimates, nowadays $2 / 3$ of the worldwide produced lithium is extracted from brines. This technology evaporates normally half a million litres of brine per ton of lithium carbonate. The process is chemicals intensive, extremely slow, and delivers large volumes of waste [43]. Methods have been searched for to speed the extraction and mitigate its environmental impact, including recovering at least some part of the water in brine as pure water.

Brines are highly saline solutions, containing typically large amounts of $\mathrm{Na}^{+}$, and lower concentrations of $\mathrm{Li}^{+}, \mathrm{K}^{+}$, $\mathrm{Mg}^{2+}$, and $\mathrm{Ca}^{2+}$. The equivalent anions generally are mainly $\mathrm{Cl}^{-}$with minor amounts of $\mathrm{SO}_{4}{ }^{2-}, \mathrm{HCO}_{3}{ }^{-}$and borates. Lithium concentration is low (in the range 0,3 $1,5 \%)$, concentrations of the other metals are high, and the chemical properties of the presenting $\mathrm{Na}^{+}$and $\mathrm{K}^{+}$are similar to those of $\mathrm{Li}^{+}$. Consequently efforts to directly precipitate $\mathrm{Li}^{+}$salts from brine lead also to precipitation of large amounts of $\mathrm{Na}^{+}$and $\mathrm{K}^{+}$salts [44]. In addition, presence of $\mathrm{Mg}$ in high concentrations is also detrimental, since it possesses greater affinity to lime as compared to lithium, leading to inefficiency in lime precipitation of $\mathrm{Li}$ and also hinders the ED separation of Li [9].

Consequently, it is essential to find process for efficient separation and recovery of lithium from brine sources. NF and ME are the membrane processes mainly used in this application.

NF and low pressure reverse osmosis (LPRO) have been studied for their ability to separate lithium from salt lake brines with an emphasis on $\mathrm{Mg}^{2+} / \mathrm{Li}^{+}$separation [45]. The results pointed that NF90 membrane was more efficient for $\mathrm{Li}^{+}$separation from a diluted brine because of its higher hydraulic permeability, lower critical pressure, its high rejection of $\mathrm{Mg}^{2+}$ (approximately $100 \%$ ), low rejection of $\mathrm{Li}$ (only $15 \%$ ), its higher selectivity between monovalent ions $(40 \%)$ obtained at lower operating pressure (below 15 bar) and its lower roughness showing decreased predisposition to fouling. However, the further step aimed to separate from the obtained permeate $\mathrm{Li}^{+}$and $\mathrm{Na}^{+}$by using the NF90 was not successful and dialysis at zero pressure was used to ensure the separation. Other authors also pointed that NF is suitable process for separation of $\mathrm{Li}^{+}$and $\mathrm{Mg}^{2+}$ from brines [46, 47].

Membrane electrolysis combined with crystallization is proposed as a new technology for lithium carbonate production from lithium-rich brines [44, 48, 49]. In the first stage brine is introduced in a membrane electrolyzer where anodic and cathodic departments are separated by anion exchange membrane. Water reduction increases the $\mathrm{pH}$ of the catholyte, and there $\mathrm{Mg}^{2+}$ and $\mathrm{Ca}^{2+}$, migrated due to the applied voltage, are removed as $\mathrm{Mg}(\mathrm{OH})_{2}$ and $\mathrm{Ca}(\mathrm{OH})_{2}$. In the second stage brine, from which $\mathrm{Mg}^{2+}$ and $\mathrm{Ca}^{2+}$ are removed, is introduced in the middle compartment of a three-compartment water electrolyzer. Anodic and cathodic compartments are separated from the middle compartment by anion-exchange (AEM) and cation-exchange (CEM) membranes correspondingly. Monovalent cations (left in the brine after the first stage) migrate from the middle compartment through a cation exchange membrane to the cathodic compartment where water electrolysis leads to alkalinisation. It is found that under the experimental conditions applied, the ionic migration rate across the CEM decreased in the order $\mathrm{Na}^{+}$ $>\mathrm{K}^{+}>\mathrm{Li}^{+}$. A side-crystallizer is attached to the cathodic compartment and $\mathrm{Na}^{+}$is recovered as $\mathrm{NaHCO}_{3}$ by introduction of $\mathrm{CO}_{2}$ in the system. At heating the bicarbonate solution, the bicarbonate is converted to carbonate solid samples. $\mathrm{Na}_{2} \mathrm{CO}_{3}$ with a purity of $99.5 \%$ of was obtained from real brine samples. Thus the solution is depleted in $\mathrm{Na}^{+}$ions and it is more suitable for $\mathrm{Li}_{2} \mathrm{CO}_{3}$ recovery in a successive stage. This solution is introduced (in the 3rd stage) into the middle of another threecompartment water electrolyzer, similar to the one applied in the 2 nd stage. Since the water is deprived of $\mathrm{Na}^{+}$ions, mainly $\mathrm{Li}^{+}$ions pass to the cathodic compartment, where, due to the alkalization caused by the electrolysis and introduction of $\mathrm{CO}_{2}, \mathrm{Li}_{2} \mathrm{CO}_{3}$ (with a purity of 93,8 wt. \%) is precipitated in a side-crystallizer, attached to the cathodic compartment. The method proposed recovers fresh water as a by-product (around $90 \%$ of the initial volume).

More on the advantages and challenges of the membrane-based technologies applied to the lithium recovery from brines till the middle of 2019 can be found in the work of $\mathrm{Li}$ and coauthors [50].

Studies development in that area hinted to the idea that an integrated membrane separation process could be a potent alternative to conventional Li recovery methods. An integrated membrane process combining NF and MD was studied for the enrichment of Li from simulated salt lake brine [9]. NF90 and NF270 NF membranes were used in experiments. It has been found that under optimum operating conditions, the $\mathrm{Mg} / \mathrm{Li}$ molar ratio changed from 10 to 0,19 when NF90 was used, and from 10 to 2,1 at NF270 use. The achieved concentration of $\mathrm{Li}$ 
from brine was 77 and 56\% for NF90 and NF270 membranes respectively. Following NF treatments, the separated Li could be further concentrated (by up to $80 \%$ ) by means of direct contact MD system. Park and coauthors [51] also confirmed the ability of the combination NF - MD to recover Li from low concentration lithium brine, as they stresses, at "one-tenth of capital cost, process time, and foot-print of the conventional process". The cost can be decreased further by using the waste heat from the industrial plants and solar energy.

Very recently a comprehensive technology for preparation of $\mathrm{Li}_{2} \mathrm{CO}_{3}$, has been proposed [52]. It includes electrochemical intercalation-deintercalation, nanofiltration, reverse osmosis, evaporation, and precipitation. In the beginning the electrochemical intercalation-deintercalation method is used to ensure maximum separation of magnesium and lithium, i.e. to obtain a low mass ratio $\mathrm{Mg} / \mathrm{Li}$. The $\mathrm{Mg} / \mathrm{Li}$ ratio decreased from 58,5 in the brine to 0,93 in the produced lithiumcontaining anolyte. Further, multivalent ions (e.g., $\mathrm{Mg}^{2+}$, $\mathrm{Ca}^{2+}$, and $\mathrm{SO}_{4}{ }^{2--}$ ) are removed from the obtained anolyte via the NF method. Then NF permeate is concentrated by RO. The next step uses evaporation to increase further the lithium concentration. Finally $\mathrm{Li}_{2} \mathrm{CO}_{3}$ is precipitated by $\mathrm{Na}_{2} \mathrm{CO}_{3}$ addition. By the proposed technology a direct recovery of lithium from the high $\mathrm{Mg} / \mathrm{Li}$ brine to the produced $\mathrm{Li}_{2} \mathrm{CO}_{3}$ can come to $68,7 \%$. When recycling is ensured for the most of the solutions in the system, the total recovery of lithium will be higher than $85 \%$.

\section{Membrane technologies for recovering reagents, metals and water from mining waste streams}

Treatment of in-plant process effluents and wastewater streams are presented in this section.

Membrane processes have been applied for treating inplant effluents in order to regenerate reagents and/or to separate valuable materials. An example is application of $\mathrm{ED}$ for recovery of $\mathrm{HCl}$, zinc and iron contained in effluents from chloride hydrometallurgy [17]. The waste stream was with high concentration of hydrochloric acid and of metal anionic and cationic chloro-complexes. Initially selective membrane-based solvent extraction step was applied to separate in raffinate cationic iron from the stripping solution that contained the $\mathrm{HCl}$ together with anionic species of zinc. The stripping solution was passed to ED system where $\mathrm{Zn}$ was concentrated in concentrate and the latter was suitable for $\mathrm{Zn}$ electrowinning. $\mathrm{HCl}$ was recovered in diluate to be re-used in the leaching process.

Another example is recycling of $\mathrm{H}_{2} \mathrm{SO}_{4}$ from raffinate, generated during copper ore hydrometallurgical processing, by use of bipolar membrane electrodialysis (BMED) system [53]. The raffinate is highly acidic and contains $\mathrm{Fe}, \mathrm{Zn}, \mathrm{Cu}, \mathrm{Ni}, \mathrm{Cr}, \mathrm{Cd}$, As in high concentrations. The experiments showed that $85,9 \%$ of $\mathrm{SO}_{4}{ }^{2-}$ that present in the raffinate could be recovered by the formation of $\mathrm{H}_{2} \mathrm{SO}_{4}$. The removal rates of other pollutants were, in $\%$ : iron - 99,3, zinc - 99,1, copper - 99,0, nickel 84,9\%, chromium - 70,6, cadmium - 95,8\%, and arsenic - 94,8.
In order to find a sustainable solution for fresh-water demand in mining sectors, MD was proposed to reclaim POX effluent [54]. Different operational conditions were studies and under the optimum ones (PTFE membrane with spacer, feed temperature $-60 \circ \mathrm{C}$, recirculation flow rate $-0,3 \mathrm{~L} / \mathrm{min}$ ), the average distillate flux was $6,82 \mathrm{~L} / \mathrm{m}^{2}$ $\mathrm{h}$ and a permeate recovery rate was $33,91 \%$ at retention rates for metals $>95,7 \%$ and for the acid $>99,9 \%$. The system was working 240 days without any deterioration of parameters, generating a permeate that can be used directly as recycled water in the plant. Since the temperature of the POX effluent is in the range $50-80{ }^{\circ} \mathrm{C}$, the effluent can be introduced directly into MD system thus decreasing the energy demand for the effluent processing.

In general, $\mathrm{RO}$ is the major membrane process used by the developed countries to treat wastewater streams from mine sites, especially with the aim to achieve water quality meeting the legislation requirements permitting water discharge in natural water bodies. Most often the technology is applied for water polishing after other treatment processes and before discharge to the environment. For example Oceana Gold - Waihi (New Zeeland) applies RO since 2008 to remove pollutants, such as TDS, Se and As left after treating the wastewater by a conventional wastewater treatment plant using chemical precipitation and clarification [22]. The water is purified to a level of purity, far in excess of that required by regulators [55].

Many mines in Australia are using the RO technology as a post-treatment process for removing heavy metals and other toxic compounds from their wastewaters before water discharge to the environment [56-58]. However, membrane fouling appears as one of the biggest problems when RO is used in a harsh environment like as mining operations.

A study evaluated the performance of RO plant as a wastewater post-treatment process in mining operations in Victoria, Australia [56]. The data analysis points that the RO treatment significantly improves the quality of the final water before it is being discharged to surface waters. Considering average rejection efficiency for the entire evaluated period (01.01.2015 - 27.11.2018), the concentrations of antimony, arsenic, nickel, zinc and iron were reduced by $95 \%, 66 \%, 82 \%, 48 \%$ and $10 \%$, respectively in the RO permeate compared to the feed water. The turbidity and TDS decreased by $85 \%$ and 96 $\%$. However, the sporadic inefficiency of the pretreatment system, led up to serious failures in RO plant, resulting in a non-compliance with local discharge licence in some days. The conclusion was that since RO membranes are very sensitive to fouling, availability of a reliable and extensive pre-treatment system is the most critical factor to guarantee good performance and high durability of membranes.

Legislative measures forced not only gold and copper mining companies but also coal-mining enterprises to search for solutions to minimize their saline wastewater. A study was carried out aimed at evaluating the performance of an integrated FO - RO system with three different actual coal mine waters from Australia, containing different concentrations of sulphates and silica 
that are usually related with scaling and fouling of membrane systems [59]. Studies have shown that the integrated system concentrated the mine water, recovering more than $80 \%$ of the mine water volume and producing treated water of dischargeable quality. It is found that the combination of FO with RO provided a better results than individual FO or RO. The FO unit performed as an effective pre-treatment system prior to RO and showed a potential to successfully replace conventional pre-treatment processes for RO.

\section{Conclusions}

Application of membrane-based processes in mining and mineral processing industry offers many potential benefits such as (a) Improved selective separation of valuable metals, (b) Water and reagents recovery for reuse in the production process, (c) Reduction of volumes requiring conventional treatments, such as lime neutralization and precipitation. This in its turn leads to decreased usage of reagents and reduced costs for disposal, (d) Release of wastewater aligned with stringent regulatory standards for water discharge to the environment and even production of water usable for industrial, agricultural, and domestic purposes, (e) Efficiently dealing with AMD and MIW.

All mentioned translates into smaller and more efficient plants with lower capital and operating costs, as well as decreased environmental negative impacts.

Flexible application of membrane based technologies, with relatively small footprint, compared to traditional technologies, can be ensured by nowadays developments in the area. While RO is still "classics" in the wastewater treatment, in in-process technology NF gains increasing attention, since RO and NF provide similar rejection performances for commodity metals and multi-valent ions and NF shows a higher flux at lower pressure, leading to lower capital investment, lower cost of operation and maintenance. MF and UF are considered as necessary and suitable pre-treatments to remove suspended solids prior $\mathrm{NF}$ and RO operations.

Among the barriers hindering the application of membrane-based processes in mining and mineral processing the following can be pointed out: (a) Still relatively high capital and operational costs, (b) Fouling and scaling of membranes, since the waters entering the membrane plant have a large amount of complex suspended and dissolved solids. Need of chemicals and pre-treatment to avoid the mentioned problems and to ensure feed solution with predictable quality, (c) Still some improvements in module design and process optimization are needed.

However, the developments of science an technology in the area of membranes and membrane technologies is going to mitigate these problems.

Hopefully, this paper will be useful in providing some information and basis for widening the application of membrane technologies in mining and mineral processing in order to render metals extraction more environmentally friendly and sustainable.

\section{References}

1. B.S. Salas, Dissertation, Escola Tècnica Superior d'Enginyeria Industrial de Barcelona, 2017

2. P. Günther, T. Naidu, in WISA Biennial Conference, Johannesburg, South Africa, paper 030 (2008)

3. H. Al-Zoubi, A. Rieger, P. Steinberger, W. Pelz, R. Haseneder, G. Härtel, Optimization study for treatment of acid mine drainage using membrane technology. Sep. Sci. Technol. 45, 2004-2016 (2010). doi.org/ 10.1080/01496395.2010.480963

4. S.P. Chesters, P. Morton, M. Fazel, in: Mining Meets Water-Conflicts and Solutions, IMWA Proceedings Freiberg, Germany, 2016, ed. by C. Drebenstedt, M. Paul

5. R. Thiruvenkatachari, S. Su, M. Cunnington, FO-RO for mining wastewater treatment. Current Trends and Future Developments on (Bio-) Membranes, Reverse and Forward Osmosis: Principles, Applications, Advances, 325-336 (2020) doi.org/10.1016/B978-012-816777-9.00014-9

6. G. Levay, R.St.C. Smart, W.M. Skinner, The impact of water quality on flotation performance. J. S. Afr. I. Min. Metall. 101, 69-75 (2001). www.saimm.co.za/ Journal/v101n02p069.pdf

7. W. Liu, C.J. Moran, S. Vink, A review of the effect of water quality on flotation. Miner. Eng. 53, 91-100 (2013) doi.org/10.1016/j.mineng.2013.07.011

8. Project BioMore, Report on "Results of PLS preconcentration, product recovery and effluent treatment. (Horizon 2020 - grant No 642456, Ares1742378 - 31/03/2017, 2017)

9. B.K. Pramanik, M.B. Asif, S. Kentish, L.D. Nghiem, F.I. Hai, Lithium enrichment from a simulated salt lake brine using an integrated nanofiltrationmembrane distillation process. J. Environ. Chem. Eng. (2019). doi.org/10.1016/j.jece.2019.103395

10. J. Song, T. Huang, H. Qiu, X. Niu, X.M. Li, Y. Xie, T. He, A critical review on membrane extraction with improved stability: Potential application for recycling metals from city mine. Desalination 440, 18-38 (2018). doi.org/10.1016/j.desal.2018.01.007

11. E.O. Ezugbe, S. Rathilal, Membrane Technologies in Wastewater Treatment: A Review. Membranes 10 (2020). doi:10.3390/membranes 10050089

12. Interstate Technology \& Regulatory Council Mining Waste Team, Pressure-Driven Membrane Separation Technologies. (Washington, 2010)

13. P. K. Parhi, Supported Liquid Membrane Principle and Its Practices: A Short Review. Hindawi J. Chem. (2013). dx.doi.org/10.1155/2013/618236

14. P. A. Mahakal, R. S. Deshpande, Removal of heavy metal from aqueous wastewater by emulsion liquid membranes. Int. J. Adv. Res. 6 (1), 455-463 (2018). DOI: $10.21474 /$ IJAR01/6242

15. J. Piia, Dissertation, University of Oulu, Faculty of Technology, 2016 
16. H. Kyllönen, E. Järvelä, J. Heikkinen, M. Urpanen, A. Grönroos, in Mine Water and Circular Economy, IMWA 2017, Lappeenranta, Finland, 2017, ed. by C. Wolkersdorfer, L. Sartz, M. Sillanpää, A. Häkkinen

17. M.F.S. Román, I.O. Gándara, E. Bringas, R. Ibañez, I. Ortiz, Membrane selective recovery of $\mathrm{HCl}$, zinc and iron from simulated mining effluents. Desalination 440, 78-87 (2018). doi.org/10.1016/j.desal.2018.02.005,

18. L.M. Zhao, Q.B. Chen, Z.Y. Ji, J. Liu, Y.Y. Zhao, X.F. Guo, J.S. Yuan, Separating and recovering lithium from brines using selective-electrodialysis: Sensitivity to temperature. Chem. Eng. Res. Des. 140, $\quad 116-127$

(2018). doi.org/10.1016/j.cherd.2018.10.009

19. Q.-B. Chen, Z.-Y. Ji, J. Liu, Y.-Y. Zhao, S.-Z. Wang, J.-S. Yuan, Development of recovering lithium from brines by selective-electrodialysis: Effect of coexisting cations on the migration of lithium. J. Membr. Sci. 548, 408-420 (2018). doi.org/10.1016/j.memsci.2017.11.040

20. Z.Y. Guo, Z.Y. Ji, Q.B. Chen, J. Liu, Y.Y. Zhao, F. Li, Z.Y. Liu, J.S. Yuan, Prefractionation of $\mathrm{LiCl}$ from concentrated seawater/salt lake brines by electrodialysi with monovalent selective ion exchange membranes. J. Cleaner Prod. 193, 338-350 (2018). doi.org/10.1016/j.jclepro.2018.05.077

21. W. Rahmah, A.K. Wardani, G. Lugito, I.G. Wenten, Membrane Technology in Deep Seawater Exploration: A Mini Review. J. Membrane Sci. Res. 6, 280-294 (2020). DOI: 10.22079/JMSR.2019.110529.1270

22. L.A. Lien, in Hydrocopper 2009, Proceedings of the V International Copper Hydrometallurgy Workshop, Antofagasta, Chile, 2009, ed. by J.M.C.de Prada, E. Domic

23. H. Bayer, in Proceedings of the 2004 Ontario MEND Workshop, Sudbury, Ontario, May 26 and 272004

24. C.M. Zhong, Z.L. Xu, X.H. Fang, L. Cheng, Treatment of acid mine drainage (AMD) by ultralow-pressure reverse osmosis and nanofiltration. Environ Eng Sci 24, 1297-1306 (2007). doi.org/10.1089/ees.2006.0245

25. S. Mortazavi, Application of membrane separation technology to mitigation of mine effluente and acidic drainage. Mine Environment Neutral Drainage Program (MEND) Report 3.15.1. (MEND and CANMET, Canada, 2008)

26. A. Rieger, P. Steinberger, W. Pelz, R. Haseneder, G. Hartel, Mine water treatment by membrane filtration processes - Experimental investigations on applicability. Desalin. Water Treat. 6, 54-60 (2009). doi.org/10.5004/dwt.2009.644

27. H. Al-Zoubi, A. Rieger, P. Steinberger, W. Pelz, R. Haseneder, G. Hartel, Nanofiltration of acid mine drainage. Desalin. Water. Treat. 21, 148-161 (2010). DOI: $10.5004 /$ dwt.2010.1316
28. D. Bacon, K. Payne, Bingham Canyon, Water Treatment Plant, Kennecott South Zone, Case Study as part of a Web-based Technical and Regulatory Guidance, Mining waste treatment technology selection

(2010)

https://www.itrcweb.org/miningwaste-

guidance/cs48_ kennecott south.htm. Accessed 23 December $202 \overline{0}$

29. World Coal Association. Case study. South Africa Anglo American eMalahleni Water Reclamation Plant - Winner of WCA Award for Excellence in Environmental Practice 2013 (WCA, 2014)

30. M. Mullett, R. Fornarelli, D. Ralph, Nanofiltration of mine water: impact of feed $\mathrm{pH}$ and membrane charge on resource recovery and water discharge. Membranes, 4, 163-180 (2014). doi:10.3390/membranes4020163

31. A.O. Aguiar, L.H. Andrade, B.C. Ricci, W.L. Pires, G.A. Miranda, M.C.S. Amaral, Gold acid mine drainage treatment by membrane separation processes: an evaluation of the main operational conditions. Sep. Purif. Technol. 170, 360-369 (2016). doi.org/10.1016/j.seppur.2016.07.003

32. L. Pino, E. Beltran, A. Schwarz, M.C. Ruiz, R. Borquez, Optimization of nanofiltration for treatment of acid mine drainage and copper recovery by solvent extraction. Hydrometallurgy (2020). doi.org/ 10.1016/j.hydromet. 2020.105361

33. F. Fu, Q. Wang, Removal of heavy metal ions from wastewaters: A review. J. Environ. Manage. 92, 407418 (2011). doi:10.1016/j.jenvman.2010.11.011

34. P. Häyrynen, J. Landaburu-Aguirre, E. Pongrácz, R.L. Keiski, Study of permeate flux in micellarenhanced ultrafiltration on a semi-pilot scale: Simultaneous removal of heavy metals from phosphorous rich real wastewaters. Sep. Purif. Technol. 93, 59-66 (2012). doi.org/10.1016/j.seppur.2012.03.029

35. D.H. Green, J.J. Mueller, US Patent 5961833, 1999

36. K. Soldenhoff, J. McCulloch, A. Manis, P. Macintosh, in Nanofiltration-principles and application, ed. by A.I. Schafer, A.G. Fane, T.D. Waite (Elsevier Science, 2004), p. 459-477

37. J.A. Lombardi, in Membrane Technology Developments for Mining Applications, Metallurgical Processes Committee, Conference: Perumin, Peru, September 2009

38. L.H. Andrade, B.C. Ricci, L.B. Grossi, W.L. Pires, M.C.S. Amaral, Comprehensive bench- and pilotscale investigation of NF for gold mining effluent treatment:membrane performance and fouling control strategies. Sep. Purif. Technol. 174, 44-56 (2017). doi.org/10.1016/j.seppur.2016.09.048

39. M.C.S. Amaral, L.B. Grossi, R.L. Ramos, B.C. Ricci, L.H. Andrade, Integrated UF-NF-RO route for gold mining effluent treatment: From bench-scale to pilotscale. Desalination 440, 111-121 (2018). doi.org/10.1016/j.desal.2018.02.030 
40. R. L. Ramos, L. B. Grossi, B. C. Ricci, M. C.S. Amaral, Membrane selection for the Gold mining pressure-oxidation process (POX) effluent reclamation using integrated UF-NF-RO processes J. Environ. Chem. Eng. (2020). doi.org/10.1016/j.jece.2020.104056

41. D.W. Nel, P. van der Gryp, H.W.J.P. Neomagus, D. Bessarabov, Application of membrane technology in a base metal refinery. J. S. Afr. I. Min. Metall. 113, 363-374 www.scielo.org.za/pdf/jsaimm/v113n4/13.pdf

42. K. Meschke, R. Hofmann, R. Haseneder, J.-U. Repke, Membrane treatment of leached mining waste - A potential process chain for the separation of the strategic elements germanium and rhenium. Chem. Eng. J. (2020). doi.org/ 10.1016/j.cej.2019.122476

43. V. Flexer, C.F. Baspineiro, C.I. Galli, Lithium recovery from brines: A vital raw material for green energies with a potential environmental impact in its mining and processing. Sci. Total Environ. 639, 1188-1204 (2018). doi.org/10.1016/j.scitotenv. 2018.05.223

44. C.H.D. Nieto, K. Rabaey, V. Flexer, Membrane electrolysis for the removal of $\mathrm{Na}+$ from brines for the subsequent recovery of lithium salts. Sep. Purif. Technol. (2020). doi.org/10.1016/j.seppur. 2020.117410

45. A. Somrani, A.H. Hamzaoui, M. Pontie, Study on lithium separation from salt lake brines by nanofiltration (NF) and low pressure reverse osmosis (LPRO). Desalination 317, 184-192 (2013). dx.doi.org/10.1016/j.desal.2013.03.009

46. X. Wen, P. Ma, C. Zhu, Q. He, X. Deng, Preliminary study on recovering lithium chloride from lithiumcontaining waters by nanofiltration. Sep. Purif. Technol. 49, 230-236 (2006). doi.org/10.1016/j.seppur. 2005.10.004

47. S.Y. Sun, L.J. Cai, X.Y. Nie, X. Song, J.G. Yu, Separation of magnesium and lithium from brine using a Desal nanofiltration membrane. J. Water Proc. Eng. 7, 210-217 (2015). doi.org/10.1016/j.jwpe. 2015.06.012

48. C.H.D. Nieto, N.A. Palacios, K. Verbeeck, A. Prévoteau, K. Rabaey, V. Flexer, Membrane electrolysis for the removal of $\mathrm{Mg}^{2+}$ and $\mathrm{Ca}^{2+}$ from lithium rich brines. Water Res. 154, 117-124 (2019). doi.org/10.1016/ j.watres.2019.01.050

49. W.R. Torres, C.H. Diaz Nieto, A. Prevoteau, K. Rabaey, V. Flexer, Lithium carbonate recovery from brines using membrane electrolysis. J. Membr. Sci. (2020). doi.org/10.1016/j.memsci.2020.118416
50. X. Li, Y. Mo,W. Qing, S. Shao, C.Y. Tang, Membrane-based technologies for lithium recovery from water lithium resources: A review. J. Membrane Sci. (2019). doi.org/10.1016/j.memsci. 2019.117317

51. S.H. Park, J.H. Kim, S.J. Moon, J.T. Jung, H.H. Wang, A. Ali, C.A. Quist-Jensen, F. Macedonio, E. Drioli, Y.M. Lee, Lithium recovery from artificial brine using energy-efficient membrane distillation and nanofiltration. J. Membr. Sci. (2020). doi.org/10.1016/ j.memsci.2019.117683

52. W. Xu, D. Liu, L. He, Z. Zhao, A Comprehensive Membrane Process for Preparing Lithium Carbonate from High $\mathrm{Mg} / \mathrm{Li}$ Brine. Membranes (2020). doi:10.3390/membranes10120371

53. Y. Liub, X. Ke, H. Zhu, R. Chen, X. Chen, X. Zheng, Y. Jin, B.V. der Bruggen, Treatment of raffinate generated via copper ore hydrometallurgical processing using a bipolar membrane electrodialysis system. Chem. Eng. J. (2020). doi.org/10.1016/j.cej.2019.122956

54. A.F.S. Foureaux, V.R. Moreira, Y.A.R. Lebron, L.V. de S. Santos, M.C.S. Amaral, A sustainable solution for fresh-water demand in mining sectors: Process water reclamation from POX effluent by membrane distillation. Sep. Purif. Technol. (2021). doi.org/10.1016/ j.seppur.2020.117797

55. Water management, (Waihi Gold, 2011), https://livewaihigold-public.pantheonsite.io/?s= Reverse+ osmosis Accessed 20 December 2020

56. S.M. Samaei, S.G. Trinidad, A. Altaee, Performance evaluation of reverse osmosis process in the posttreatment of mining wastewaters: Case study of Costerfield mining operations, Victoria, Australia. J. Water Proc. Eng. (2020). doi.org/ 10.1016/j.jwpe.2019.101116

57. Citor Desalinators, Mine Site Archives (2020) http:/www. citor.com.au/product-category/minesites/. Accessed 20 December 2020

58. Australian mining, Veolia to deliver water treatment plant at gold mine https:/www.australianmining.com.au/ news/veoliadeliver -water-treatment-plant-gold mine. Accessed 20 December 2020

59. R. Thiruvenkatachari, M. Francis, M. Cunnington, S. $\mathrm{Su}$, Application of integrated forward and reverse osmosis for coal mine wastewater desalination. Sep. Purif. Technol. 163, 181-188 (2016). doi.org/10.1016/ j.seppur.2016.02.034 